\title{
MOLECULAR MARKERS AND SENTINEL ORGANISMS FOR ENVIRONMENTAL MONITORING
}

\author{
GRACZYK T.K.*,**,**** \& CONN D.B.*****
}

\section{Summary:}

Molecular methods are useful for both to monitor anthropogenic viral, bacterial, and protozoan enteropathogens, and to track pathogen specific markers in a complex environment in order to reveal sources of these pathogens. Molecular genetic markers for fecal viruses, bacteria, and protozoans hold promise for monitoring environmental pollution and water quality. The demand for microbiologically safe waters grows exponentially due to the global demographic rise of the human population. Economically important shellfish, such as oysters, which are harvested commercially and preferentially consumed raw can be of public health importance if contaminated with human waterborne pathogens. However, feral molluscan shellfish which do not have an apparent economic value serve as indicators in monitoring aquatic environments for pollution with human waterborne pathogens and for sanitary assessment of water quality. Current technology allows for multiplexed species-specific identification, genotyping, enumeration, viability assessment, and source-tracking of human enteropathogens which considerably enhances the pathogen source-tracking efforts.

KEY WORDS : microbiological monitoring, fecal contamination, fecal source discrimination, molecular markers, sentinel organisms.

$\mathrm{F}$ ecal contamination of aquatic environments afflicts many regions of the world with associated human health risks and environmental damage. Fecal pollution spreads a variety of dangerous viral, bacterial, and protozoan pathogens such as hepatitis, Norovirus, Salmonella spp., Shigella spp., Campylobacter spp., Escherichia coli (E. coli) O157:H7, Cryptosporidium spp., Giardia lamblia, Cyclospora cayetanensis, and humanvirulent microsporidia (i.e., Enterocytozoon bieneusi, Encephalitozoon intestinalis, E. hellem, and E. cuniculi)

\footnotetext{
* Department of Environmental Health Sciences, Division of Environmental Health Engineering, Johns Hopkins Bloomberg School of Public Health, Baltimore, Maryland 21205, USA.

*** Johns Hopkins Center for Water and Health, Johns Hopkins Bloomberg School of Public Health, Baltimore, Maryland 21205, USA.

**** Department of Molecular Microbiology and Immunology, Johns Hopkins Bloomberg School of Public Health, Baltimore, Maryland 21205, USA.

***** School of Mathematical and Natural Sciences, Berry College, Mount Berry, Georgia 30149, USA

Correspondence: T. K. Graczyk, Department of Environmental Health Sciences, Division of Environmental Health Engineering, Johns Hopkins Bloomberg School of Public Health, Baltimore, Maryland 21205, USA. Tel.: 4106144984 - Fax: 4109550105.

E-mail: tgraczyk@jhsph.edu
}

(Field et al., 2003; Graczyk et al., 2007a). Cryptosporidium, Giardia, and microsporidia inflict considerable morbidity on healthy people and can cause mortality (e.g., Cryptosporidium) in immunosuppressed individuals (Graczyk et al., 2007a). Cryptosporidium and Giardia are very frequently transmitted via water, and numerous reports indicate involvement of water in the epidemiology of microsporidian spores (Graczyk et al., 2007a). They transmissive stages, i.e., oocysts, cysts, and spores, are environmentally-robust and therefore ubiquitous in aquatic habitats (Graczyk et al., 2007a). These protozoan enteropathogens are category B biodefense agents on the National Institute of Health list, and microsporidian spores are on Contaminant Candidate List of the U.S. EPA because spore identification, removal, or inactivation in drinking water is technologically challenging. Drinking water source or recreational waters are not routinely monitored for these pathogens, and considerable evidence demonstrates their direct zoonotic association with animals. Very often the source of fecal contamination cannot be determined because failing septic systems, wastewater discharges, and surface runoff from point and non-point sources may equally contribute to environmental contamination) (Field et al., 2003). Sewage wastewater discharges are worldwide risk factors for the introduction of human enteropathogens into surface waters. In addition, although water sediments are known to be a source of human enteropathogens, the contribution of pathogen pollution deposited in sediments and re-suspended during storm events relative to other sources is unknown) (Field et al., 2003). In order to adequately assess human health risks and develop management plans for watersheds that providing drinking water and supporting recreation and fisheries, it is necessary to know the sources of fecal contamination (Graczyk et al., 2007a).

\section{BACTERIAL PATHOGENS AND METHODS FOR DETECTING THEIR SOURCES}

$\mathrm{F}$ or bacterial pathogens, the standard method of measuring fecal pollution does not distinguish between human and animal sources (Field et al., 
2003). The method requires growing fecal coliforms or E. coli from water samples to estimate their concentrations. Because these bacteria are found in a variety of warm-blooded animals, this method does not distinguish between human and animal sources (Field et al., 2003). In addition, coliform-based methods can be confounded by growth of coliforms in receiving water and sediments (Field et al., 2003). Coliforms adhere to sediments and are transported in and out of the water column, affecting the measure of fecal pollution in unknown ways (Field et al., 2003). It is remarkable that although coliforms are the gold standard for measuring fecal pollution, the influences of these important factors are still so poorly understood (Field et al., 2003). Several methods for identification of the source of fecal pollution have been used, but each has drawbacks. The ratio of fecal streptococci to fecal coliforms has been used to differentiate human $v$ s animal sources (Sinton et al., 1993). However strains of coliforms and streptococci have different environmental survival rates, and because the ratio changes over time - it is unreliable. Antibiotic resistance patterns of fecal streptococci or coliforms can distinguish among sources of fecal pollution (Wiggins et al., 1999). However this method requires culturing a large number of fecal streptococcal isolates, and therefore, it is labor-intensive and time-consuming. Escherichia coli ribotyping (Carson et al., 2001) and rep-PCR DNA fingerprinting (Dombek et al., 2001) are genotyping methods that depend on growing a large number of isolates. Ribotyping can discriminate between human and non-human isolates, but is less efficient at identifying animal sources. Both these methods require large local collections of strains for comparison purposes. Phage can be used as indicators of fecal pollution (Havelaar et al., 1993). Although coliphage abundance is well correlated with sewage effluent (Paul et al., 1997); coliphage are also associated with non-point discharge (Paul et al., 1997). Coliphage can indicate the presence of human enteric viruses in water (Havelaar et al., 1993); however, their use is limited because only a small portion of fecal bacteria may contain phages, and virus concentrations in sewage are highly variable (Havelaar et al., 1993). All of the aforementioned methods are time consuming, labor intensive, require specialized equipment or extensive strain collections, are subject to culture bias, and may have unacceptably low rates of accuracy.

Source-tracking is commonly used to relate to bacterial overload and waterborne transport. However, fecal coliform source-tracking technology is not easily adoptable by wastewater facilities because of its sophistication. In addition, multiple studies have already shown the inadequacy of standard fecal coliforms (i.e., E. coli, enterococci, fecal and total coliforms) as indicators of contamination of drinking, recreational, and wastewaters with human viral and protozoan enteropathogens.

\section{RECOVERY AND IDENTIFICATION OF CRYPTOSPORIDIUM FROM ENVIRONMENTAL MATRICES}

$\mathrm{R}$ ecovery of Cryptosporidium oocysts from environmental-matrices remains a technologically complex process, but even more challenging is subsequent species-specific identification and viability assessment of the oocysts (Graczyk et al., 2007b). Microscopy has a low sensitivity and requires a skilled microscopist. Immunofluorescent antibody (IFA) usually overestimates the Cryptosporidium load because IFA cross-reacts with other species of Cryptosporidium not virulent for humans, small unicellular algae, and non-viable oocysts (Graczyk et al., 2007b). PCR-based methods, although very sensitive and specific, do not allow for viability assessment, and are highly sensitive for massive amounts of PCR inhibitors present in environmental samples. Vital dyes, e.g., DAPI/PI stains, can be used for viability assessment; however, these stains are not Cryptosporidium-specific and produces positive reactions with any organism that have nucleic acid (Graczyk et al., 2007b).

There is currently no consensus on the best method for determining species/genotype of Cryptosporidium. Since Cryptosporidium species cannot be differentiated based on oocyst morphology, a number of molecular techniques have been developed for species identification and analysis of genetic diversity. There is very little data on how results generated using different genotyping methods correlate. All of these techniques are based on PCR amplification of a DNA region with reasonable genetic variability between and within species. In some cases, a single round of PCR amplification is sufficient, though more often, a nested PCR is performed to improve sensitivity. Following PCR amplification, species determination is most often carried out by restricted fragment length polymorphism (RFLP), in which the PCR product is digested with restriction enzymes and the resulting DNA fragments are visualized and compared to standard fragment profiles for each known species. Cryptosporidium genes that are frequently used for this purpose include the small subunit rRNA gene (SSU rRNA), the Cryptosporidium outer wall protein (COWP) gene, the heat shock protein 70 (HSP70) gene, the glycoprotein 60 (GP60) gene and the thrombospondin-related adhesive protein (TRAP) gene. Once the species has been determined, further genotyping can be carried out by DNA sequence analysis of the amplified gene. Some alternative methods that don't involve DNA sequencing are multi-locus genotyping by microsatellite analysis and single strand conformation polymorphism (SSCP) analysis of the internal transcribed spacer (ITS-2) region of the nuclear 
ribosomal DNA gene. Both of these alternative methods can be used to determine species without RFLP analysis. A recent study compared multiple genotyping methods. Though all methods tested provided valuable results, SSCP analysis of the ITS-2 rDNA gene was superior in identifying genetic variants and mixed infections. This method was also considered to be most cost-effective for analyzing large numbers of samples.

\section{ENUMERATION AND ASSESSMENT OF CRYPTOSPORIDIUM INFECTIVITY/VIABILITY}

M ost of the PCR-based methods used for screening samples and genotyping provide no information on numbers of Cryptosporidium oocysts present or the viability/infectivity of those oocysts. Several assays have been developed to provide this type of epidemiologically-important data. The gold standard is an animal bioassay using neonatal mice. This method is frequently used to assess oocyst infectivity after treatment with disinfectants. Treated oocysts are administered to neonatal mice orally, and after a sufficient incubation period, oocyst infectivity can be assessed by quantifying oocysts shed in fecal matter or identifying developmental stages of the parasite in fixed and stained sections of the intestine. Alternatively, sections of intestine can be homogenized and parasites present in the homogenate can be detected by flow cytometry or PCR. However, there are several disadvantages to using animal bioassays. First, neonatal mice cannot be infected with all species of Cryptosporidium, including the human-specific species, C. bominis. Though a gnotobiotic pig model has been developed to overcome this limitation, bioassays are significantly more expensive than in vitro assays for infectivity and bring up issues of animal bioethics. Several cell culture-based methods have been shown to be just as effective as animal bioassays for assessing oocyst infectivity and inactivation by disinfectants. After exposing cell cultures to treated oocysts, infectivity can be assessed by staining infected cells using a Cryptosporidium-specific IFA. Alternatively, Cryptosporidium DNA can be extracted from the infected cultures and detected by PCR amplification. The use of a quantitative real-time PCR on DNA extracted from infected cell cultures can allow quantification of oocyst infectivity. The fluorescent in situ hybridization (FISH) provides both, species-specific quantitative identification with simultaneous viability assessments of Cryptosporidium oocysts (Graczyk et al., 2006). The FISH method utilizes fluorescently-labeled oligonucleotide probes, i.e., CRY-1, designed to hybridize with specific sequences of $18 \mathrm{~S}$ rRNA of $C$. parvum and C. hominis. Because rRNA is only present in large copy numbers in viable organisms, FISH allows species-specific identification by providing visualization of viable oocysts and cysts, and facilitates their enumeration (Graczyk et al., 2006). Furthermore, multiplexed FISH has been combined with a direct immunofluorescent antibody (IFA) against the wall antigens of Cryptosporidium, and this approach has been successful for simultaneous detection of $C$. parvum, and $C$. hominis in environmental and clinical samples (Graczyk et al., 2006).

\section{HUMAN WATERBORNE PATHOGENS IN MOLLUSCAN SHELLFISH}

M olluscan shellfish are suspension- or sediment-feeding organisms, which filter unicellular algae, bacteria, other microorganisms, and detrital particles of approximately 1-30 $\mu \mathrm{m}$ size range. Bivalves have an important role in aquatic habitats; by filtering suspended particles they clarify the water and generally improve water quality. The diameter of transmissive stages of Cryptosporidium, Cyclospora, and Toxoplasma does not exceed 6 and $10 \mu \mathrm{m}$, respectively, and Giardia cysts are oval and no longer than $15 \mu \mathrm{m}$. Microsporidian spores range from 1.5 to $4 \mu \mathrm{m}$. Thus, cystic stages of these parasites fall within the range of particles filtered by bivalve mollusks. Multiple in vitro and in vivo experimental studies demonstrated that aforementioned parasites can be efficiently recovered from water, then retained and concentrated in shellfish. Historically, C. parvum oocysts of waterborne origin were first identified in the tissue of blue mussels in Ireland (Chalmers et al., 1997), initiating worldwide investigation of this pathogen in molluscan shellfish (Graczyk, 2003). Since then, multiple studies demonstrated that these filter-feeding organisms can harbor environmentally derived protozoan parasites as a result of concentrating the recovered particles (Graczyk, 2003). A recent and interesting epidemiological discovery is the identification, for the first time, of human-infectious microsporidia spores, i.e., E. intestinalis and E. bieneusi in molluscan shellfish, zebra mussels (Dreissena polymorpha) Graczyk et al., 2004). Microsporidia infects a variety of vertebrate and invertebrate hosts, and approximately 14 species have been reported to infect people. Of these E. intestinalis and E. bieneusi have been reported to be zoonotic and to infect domestic animals and livestock (Slodkowicz-Kowalska et al., 2006). Although the actual transmission route of this specific spore species is not known, it is quite possible that infectious spores of human or animal origin passed to the aquatic environments via feces or urine (Graczyk et al., 2004).

Cryptosporidium oocysts have also been identified in feral bivalves, supporting the concept that estuarine 
shellfish can be used in the sanitary assessment of water quality as biological indicators for contamination of water and sediment (Graczyk et al., 2004). Zebra mussels and Corbicula clams very efficiently concentrate C. parrum and G. lamblia in relation to low ambient concentrations (Graczyk et al., 2004). Bivalves such as zebra mussels or Corbicula clams are convenient for such purposes because they form dense populations and clusters that facilitate the collection of large samples, do not have economic value, have a relatively small size, and are easily collected throughout the year (Graczyk et al., 2004).

\section{QUANTITATIVE ESTIMATION OF REMOVAL OF WATERBORNE PATHOGENS BY MOLLUSCAN SHELLFISH}

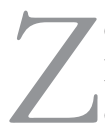

ebra mussels collected from the St.-Lawrence River, Canada, near a wastewater discharge site contained on average approximately 440 C. parvum oocysts/mussel (Graczyk et al., 2001). Knowing the $C$. parvum retention rate as $4.9 \times 10^{2}$ oocysts/mussel/24 $\mathrm{h}$ and $D$. polymorpha densities of approximately 30000 specimens $/ \mathrm{m}^{2}$ for adult (> 1-year-old) mussels, it has been calculated that during $24 \mathrm{~h}$ approximately $1.3 \times 10^{7}$ waterborne $C$. parvum oocysts can be removed by each square meter of mussel bed in the St.Lawrence River (Graczyk et al., 2001).

The concentration of $C$. parvum observed in zebra mussels from the Shannon River, Ireland (Graczyk et al., 2004) was much lower than that reported from the St.Lawrence River (Graczyk et al., 2001). However, in the St Lawrence River, mussels originated from sites impacted by wastewater discharge, and in the Shannon River, no apparent sources of water contamination have been identified near any of the sites. Considering the natural densities of zebra mussels and the fact that on average approximately eight parasites/mussel have been identified in the Shannon River study (Graczyk et al., 2004 ), at least $2.4 \times 10^{5}$ pathogens $/ 24 \mathrm{~h}$ can be potentially removed per each square meter of zebra mussel bed in the Shannon River.

\section{A PUBLIC HEALTH THREAT FROM SHELLFISH CONTAMINATED WITH WATERBORNE PATHOGENS}

$\mathrm{P}$ rior to 1992, the association between contamination derived from animal fecal wastes and the occurrence of shellfish-vectored illnesses was inconclusive (Graczyk, 2003). In 1994, enterohemorrha- gic E. coli 0157 became a major concern. This bacterium has not been associated with shellfish; however, its frequent occurrence in cattle indicated potential public health problems with shellfish harvested from waters affected by runoff from cattle farms. Beginning in 1998, multiple studies worldwide indicated that molluscan shellfish intended for human consumption can be contaminated with Cryptosporidium. So far there has been no reported outbreak (or case) of foodborne cryptosporidiosis linked to consumption of raw oysters in the US. However, (A) over $40 \%$ of all foodborne infections linked to oyster consumption are in the category of an unknown etiologic agent; (B) $20 \%$ of the general US population are vulnerable to C. parvum infection; (C) epidemiology of enteric infections, i.e., cryptosporidiosis, indicates an association with consumption of raw shellfish; and (D) it is believed that in the United States and Canada the true incidence of shellfish-vectored gastroenteritis is underestimated as much as 20 -fold. Since there is no mandatory federal requirement for reporting of gastroenteritis of an unspecified nature, physicians and state health departments are not forwarding case reports to federal authorities. In intensive seafood production regions such as northwest Gallicia, Spain, where molluscan shellfish production is the most important industry, cases of selflimiting diarrhea associated with consumption of raw oysters and clams are often reported (Graczyk, 2003).

\section{ACKNOWLEDGEMENTS}

W e apologize for not citing all original articles due to space constrains. The studies on molluscan shellfish and human pathogens were supported by the Fulbright Senior Specialist Fellowship (grant no. 2225 to Graczyk), Johns Hopkins NIEHS Center in Urban Environmental Health (grant no. P30 ES03819), Johns Hopkins Faculty Research Innovation Fund, Johns Hopkins Center for a Livable Future, and U.S. Environmental Protection Agency Science to Achieve Results (STAR) Program (grant no. RD83300201). The views expressed herein have not been subjected to the U.S. EPA review and therefore do not necessarily reflect the views of the agency, and no official endorsement should be inferred.

\section{REFERENCES}

Carson C.A., Shear B.L., Elleshiek M.R. \& Brunk C.A. A computer analysis of primer and probe hybridization potential with bacterial small-subunit rRNA sequences. Applied Environmental Microbiology, 1996, 62, 827-879.

Chalmers R.M., Chalmers A.P., Sturdee P., Mellors V., Lawrol F., Nicholson F., Kenny F. \& Timpson P. Cryptosporidium par- 
vum in environmental samples in the Sligo area, Republic of Ireland: A preliminary report. Letters in Applied Microbiology, 1997, 25, 380-384.

DombeK P.E., Johnson L.K., Zimmerley S.T. \& SADOVsKy M.J. Use of repetitive DNA sequences and the PCR to differentiate Escherichia coli isolates from human and animal soureces. Applied and Environmental Microbiology, 2001, 66, 2572-2577.

Field K.G., Bernhard A.A. \& Brodeur T.J. Molecular approaches to microbiological monitoring: fecal source detection. Environmental Monitoring and Assessment, 2003, 81, 313326.

GraczYK T.K. Human waterborne parasites in molluscan shellfish. Journal of Parasitology, 2003, 89, 557-561.

GRACZYK T.K. \& LUCY F.E. Quality of reclaimed waters; a public health need for source-tracking of wastewater-derived protozoan enteropathogens in engineered wetlands. Transactions of the Royal Society of Tropical Medicine and Hygiene, 2007a, 101, 532-533.

Graczyk T.K., Marcogliese D.J., de Lafontaine Y., Da Silva A.J, Mhagami-Ruwende B. \& PieniawzeK N. Cryptosporidium parvum oocysts in zebra mussels (Dreissena polymorpha): evidence from the St.-Lawrence River. Parasitology Research, 2001, 87, 231-234.

Graczyk T.K., Conn D.B., Lucy F., Minchin D., Tamang L., MOURA L.N.S. \& DA Silva A.J. Human waterborne parasites in zebra mussels (Dreissena polymorpha) from the Shannon River drainage, Ireland. Parasitology Research, 2004, 93, 389-391.

Graczyk T.K., Girouard A.S., Tamang L., NAPpier S.P. \& SCHWAB K.J. Recovery, bioaccumulation, and inactivation of human waterborne pathogens by the Chesapeake Bay non-native oyster, Crassostrea ariakensis. Applied and Environmental Microbiology, 2006, 72, 3390-3395.

Graczyk T.K., Lewis E.J., Glass G, Da Silva A.J, Tamang L., GIROUARD A.S. \& CuRriero F.C. Quantitative assessment of viable Cryptosporidium parvum load in commercial oysters (Crassostrea virginica) in the Chesapeake Bay. Parasitology Research, 2007b, 100, 247-253.

Havelaar A.H., van Olphen M. \& Drost Y.C. F-specific RNA bacteriophages are adequate model organisms for enteric viruses in fresh water. Applied Environmental Microbiology, 1993, 59, 2956-2962.

Paul J.H., Rose J.B., Jiang S.C., London P., Xhou X. \& KelLOGG C. Coliphage and indigenous phage in Mammala Baym Oahu, Hawaii, Applied and Environmental Microbiology, 1997, 63, 133-138.

SinTon L.W., Donnison A.M. \& Hastie C.M. Faecal streptocooci as faecal pollution indicators: a review. New Zealand Journal on Marine Freshwater Research, 1993, 27, 117-137.

Slodkowicz-Kowalska A., Graczyk T.K., Tamang L., JedrzeJEWski S., Nowosad A., Zduniak P., Soalarczyk P., Girouard A.S. \& MAjEwska A.C. Microsporidia species known to infect humans are present in aquatic birds; implications for transmission via water? Applied and Environmental Microbiology, 2006, 72, 4540-4544.

Wiggins B.A., Andrews R.W., Conway R.A., Corr C.L., Dobratz E.J., Dougherty D.P., Eppard J.R., KNupp S.R., LIM- joco M.C., Mettenburg J.M., Rinenhardt J.M., Sonsono J., TorRijos R.L. \& ZImmermann M.E. Use of antibiotic resistance analuysis to identify nonpoint sources of fecal pollution. Applied and Environmental Microbiology, 1999, 65, 3483-3486. 